\title{
Membranoproliferative glomerulonephritis and a rare bleeding disorder: factor $\mathbf{X}$ deficiency
}

\author{
T. Basturk • E. Ahbap • B. Eroglu Kesim • \\ M. Yılmaz $\cdot$ Y. Koç $\cdot$ T. Sakacı $\cdot$ A. Unsal
}

Received: 25 April 2010/Accepted: 27 August 2010/Published online: 23 September 2010

(C) The Author(s) 2010. This article is published with open access at Springerlink.com

\begin{abstract}
Factor X (FX) deficiency is a rare hereditary coagulation disorder. This is the first case report on the association of FX deficiency and membranoproliferative glomerulonephritis (MPGN) type I. The patient, a 17-year-old male, presented with edema, hypertension, and microscopic hematuria, followed by a mild upper respiratory tract infection. Laboratory tests revealed: serum creatinine $1.6 \mathrm{mg} / \mathrm{dl}$, serum albumin $2.80 \mathrm{~g} / \mathrm{dl}, \quad \mathrm{C} 316 \mathrm{mg} / \mathrm{dl}$ and proteinuria $(1,800 \mathrm{mg} /$ day $)$. The renal biopsy showed MPGN type I. The coagulation profile prior to percutaneous renal biopsy revealed prolonged prothrombin time and activated partial thromboplastin time values. The patient was given fresh frozen plasma and vitamin $\mathrm{K}$ before the biopsy. Further evaluation showed the functional activity of FX was $7 \%$ of the norm. This case emphasizes the need for routine coagulation screening before percutaneous renal biopsy.
\end{abstract}

T. Basturk ( $\bowtie)$

Department of Nephrology, Bagcilar Research and Education Hospital, 80650 Istanbul, Turkey e-mail: tanerbast@yahoo.com

E. Ahbap · M. Yılmaz · Y. Koç · T. Sakacı · A. Unsal Department of Nephrology, Sisli Etfal Research and Education Hospital, Istanbul, Turkey

B. Eroglu Kesim

Departman of Genetics, Sisli Etfal Research and Education Hospital, Istanbul, Turkey
Keywords MPGN Type I - Factor X deficiency · Percutaneous renal biopsy

\section{Introduction}

Congenital factor $\mathrm{X}$ deficiency is an extremely rare autosomal recessive disorder affecting both genders with an incidence of 1:500.000-1.000.000. An even more uncommon situation of acquired deficiency of factor $\mathrm{X}$ activity has also been described in addition to the inherited deficiency. This occasionally occurs in patients with liver diseases, vitamin K deficiency, amyloidosis, multiple myeloma, mycoplasma pneumoniae infection, leprosy and methyl bromide exposure [1-5].

The normal FX plasma levels are $8-10 \mu \mathrm{g} / \mathrm{ml}$. Half-life in plasma is $34-40 \mathrm{~h}$. This factor plays a crucial role in the coagulation cascade. It is activated either by factor VIIa/TF (tissue factor) complex via extrinsic pathway or by IXa/VIIIa complex via intrinsic pathway. The functional activity of factor $\mathrm{X}$ required for surgical hemostasis is $10-40 \%$ of the normal activity. Patients with mild to moderate deficiency remain asymptomatic until stressed by trauma or surgery. Subclinical coagulation disorders that are not evident from the patient's clinical history and examination could only be revealed by biochemical assessment $[2,6,7]$.

The association of FX deficiency with membranoproliferative glomerulonephritis (MPGN) has never 
been reported so far. We present a case of MPGN type I associated with asymptomatic mild FX deficiency and abnormal coagulation tests, discovered before the percutaneous renal biopsy. This case emphasizes the need for routine coagulation screening in patients undergoing percutaneous renal biopsy.

\section{Case report}

The patient, a 17-year-old male, presented with edema, hypertension and microscopic hematuria, followed by a mild upper respiratory tract infection. Laboratory work-up revealed an elevated serum creatinine $(1.6 \mathrm{mg} / \mathrm{dl}$, normal range: $0.5-1.2 \mathrm{mg} / \mathrm{dl})$, a decreased serum albumin $(2.80 \mathrm{~g} / \mathrm{dl}$, normal range: $3.5-5.2 \mathrm{~g} / \mathrm{dl}$ ), a low serum complement component 3 (C3) $(16 \mathrm{mg} / \mathrm{dl}$, normal range: $85-200 \mathrm{mg} / \mathrm{dl})$ and proteinuria $(1,800 \mathrm{mg} /$ day, normal range: $0-150 \mathrm{mg} /$ dl). Serology was negative for antinuclear, antidouble stranded DNA and anti-neutrophil cytoplasmic antibodies. A renal biopsy was therefore indicated.

The patient was found to have prolonged prothrombin time (PT) (22.2 s-control 10-14 s) and activated partial thrombin time (aPTT) (43.8 s-control 26-40 s). The patient's clinical history was not suggestive for coagulation disorders (i.e. no bruising, nosebleed, hematoma or excess bleeding after minor trauma or neurological deficits). There was no history of fever, jaundice or exposure to toxic substances or drugs interfering with coagulation or platelet function either. There was also no family history of bleeding disorders. On physical examination, we found no purpura, joint swelling or organomegaly.

Percutaneous renal biopsy was performed after fresh frozen plasma $(15-20 \mathrm{ml} / \mathrm{kg})$ and vitamin $\mathrm{K}$ $(20 \mathrm{mg})$ administration. The only complication encountered was the development of macroscopic hematuria 10 days after the biopsy.

Further investigations revealed normal liver function. Subsequently, FX, FII and FV activity tests were performed revealing FX activity to be 7\%, FII activity $130 \%$ and $\mathrm{FV}$ activity $94 \%$ (reference range: $70-120 \%$ ) of the norms.

The patients' family evaluation found the PT and aPTT in his mother and in one of his sisters were in normal range, while his father, another sister and two brothers had prolonged coagulation times. The FX activity in the father, the second sister and the two brothers were $18,8,12$ and $9 \%$ of the norm, respectively. The other factors of the coagulation cascade were normal in all family members.

Subsequent genetic study in the patient and his family members with FX deficiency revealed a homozygous Glu310Lys mutation in exon 8 of the FX gene (Fig. 1).

The patient's renal biopsy showed MPGN Type I. $\mathrm{He}$ was subsequently treated with prednisolone, omeprazole, and angiotensin-converting enzyme inhibitors. At the end of the first year of treatment, the patient showed improved serum creatinine $(1 \mathrm{mg} /$ $\mathrm{dl})$ and serum albumin $(4.0 \mathrm{~g} / \mathrm{dl})$ and a significant reduction in proteinuria $(200 \mathrm{mg} /$ day $)$. Meanwhile, the coagulation tests (PT:18.6 s, aPTT:38.2 s) and the FX activity level (10\%) did not change significantly (Table 1).

\section{Discussion}

Factor X, also known as the Stuart-Prower factor, is a vitamin K-dependent serine protease that serves as the first enzyme in the common pathway of thrombus formation. The FX gene is $22 \mathrm{~kb}$-long and is located at $13 \mathrm{q} 34$-ter, $2.8 \mathrm{~kb}$ downstream from the factor VII gene. Because of the central role of this factor in the clotting cascade, the complete absence of FX is lethal. Hence, mutations of factor $\mathrm{X}$ are thought to be rare, although approximately 71 different types have been reported $[2,10]$.

The bleeding tendency of factor $\mathrm{X}$ deficiency is severe and correlates with factor levels. People can suffer from bleeding when the FX level falls below $10 \%$ of normal. As a general rule, patients with FX activity levels above $10 \%$ are asymptomatic, those with FX levels in the range of 1 to $10 \%$ present with mild or moderate bleeding, whereas those with FX levels below $1 \%$ experience severe bleeding. The most common reported spontaneous bleeding symptom is epistaxis but gastrointestinal bleeding, hemarthrosis, menorrhagia, hematuria, soft tissue bleeding and umbilical cord bleeding have also been reported. Mild deficiency (plasma FX levels between $6-10 \mathrm{IU} / \mathrm{dl}$ ) may be identified only during family studies [8, 9].

The prevalence of FX deficiency is greater among populations in which consanguineous marriage is 
lwhons lowlonds

Lummon lWhany

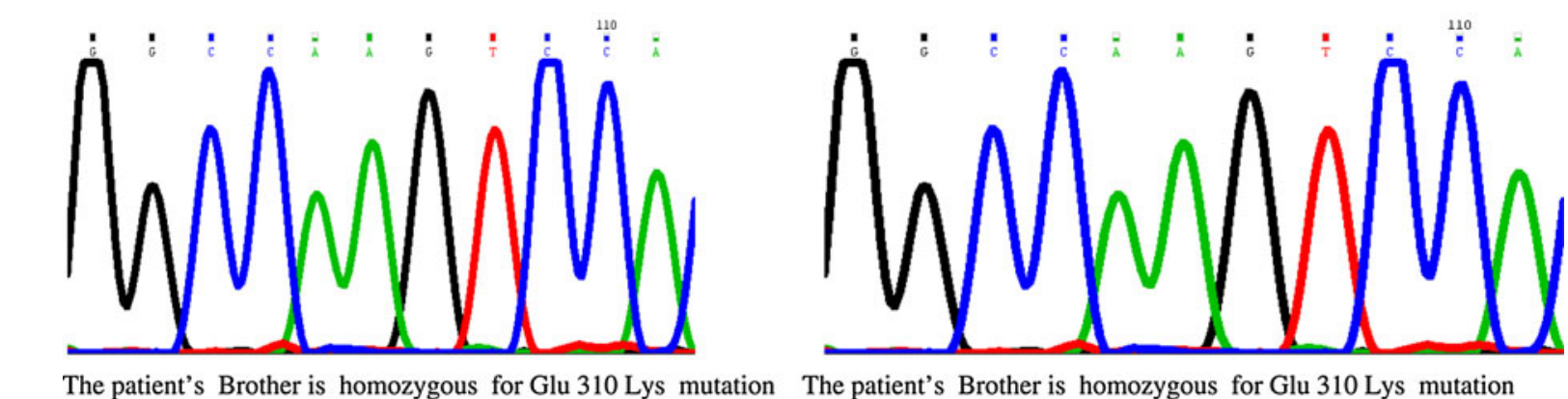

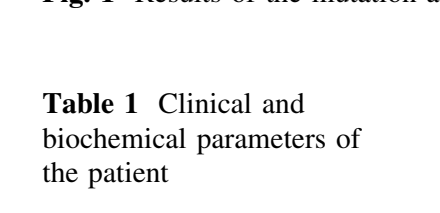


may compete with its normal counterpart to form a complex with prothrombin and reduce the formation of an active prothrombinase complex [10, 11].

The PT and the aPTT are prolonged in patients with FX deficiency. The Russell viper venom time is also prolonged in these patients; (Russell viper venom cleaves factor $\mathrm{X}$ to produce active factor $\mathrm{Xa)}$. Bleeding time is within the reference range in patients with factor $\mathrm{X}$ deficiency. The diagnosis can be confirmed by measuring the plasma FX levels. The following assays for this measurement are available: (1) the one-stage PT- and aPTT-based assays; (2) a chromogenic assay; (3) the Russell viper venom assay; and (4) an immunological assay (such as an enzyme-linked immunosorbent assay). The PT- and aPTT-based assays are usually sufficient for diagnosis, and further tests are required only for detailed protein characterization $[2,10]$.

There is no general agreement in guidelines for the management of FX deficiency. The treatment has an individual approach for each patient. However, restoring circulating FX levels to $10-40 \%$ of normal is usually adequate. Therapy involves replacement of FX with either fresh frozen plasma or prothrombin complex concentrates. Fresh frozen plasma does not contain adequate quantities of FX and is usually given when specific replacement therapy is not available. Virally inactivated plasma should be used at a dose of $20 \mathrm{ml} / \mathrm{kg}$ followed by $3-6 \mathrm{ml} / \mathrm{kg}$ twice daily, aiming to keep the trough levels of FX higher than 10-20 IU/dl. Recombinant FVIIa has been used in adults to treat amyloidosis-related FX deficiency, but there is no evidence supporting its use in patients with hereditary FX deficiencies [12].

Prothrombin complex concentrate has been used as a regular prophylaxis in these patients. Authors of one report described using $30 \mathrm{U} / \mathrm{kg}$ twice weekly as a home treatment. If breakthrough bleeding occurred, another dose was administered, but not more than two doses within $24 \mathrm{~h}$ or 3 consecutive days. However, there is a risk of thromboembolic complication when 2-3 standard doses are administered in $48 \mathrm{~h}$ [13].

Vitamin K administration may be useful in certain patients with acquired FX deficiency. Patients with inherited deficiency do not respond to vitamin $\mathrm{K}$ administration and, in fact, this lack of response helps to establish the diagnosis of this disorder [2].

The prognosis for patients with FX deficiency depends on the etiology and severity of the disease.
While acquired FX deficiency may be eliminated by treating the underlying cause, the congenital form of the disease is lifelong and is among the most severe clotting factor disorders. In general, patients with very low levels of functional FX have a greater tendency to hemorrhage and face a greater risk of life-threatening complications [14, 15].

On the other hand, we know that tissue factor initiates the extrinsic coagulation pathway by activating coagulation factor $\mathrm{X}$ to factor $\mathrm{Xa}$, and $\mathrm{Xa}$ factor is known to promote the proliferation of mesangial cells in culture. In animal models, DX-9065a, a specific Xa factor inhibitor, proved to reduce proteinuria and to significantly reduce the size of glomeruli, the total number of glomerular cells and crescent formation. So, factor X deficiency should modify the evolution of this proliferative GN [16-18].

\section{Conclusions}

Although the patient had no personal or family history suggestive of coagulation disorder, routine screening revealed abnormal PT and aPTT. Therefore, normal clinical history and physical examination do not exclude mild to moderate coagulation disorders.

Although the incidence of FX deficiency is rare, this diagnosis should be considered when patients present with bleeding diathesis or abnormal coagulation tests. Coagulation testing before performing percutaneous renal biopsy is very important, as demonstrated by this case.

Acknowledgments We thank the family members who participated in this study. We also thank Duzen Laboratories, Istanbul, Turkey, for allowing us to use their DNA sequencer

Open Access This article is distributed under the terms of the Creative Commons Attribution Noncommercial License which permits any noncommercial use, distribution, and reproduction in any medium, provided the original author(s) and source are credited.

\section{References}

1. Peuscher FW, van Aken WG, van Mourik JA, Swaak AJ, Sie LH, Statius van Eps LW (1979) Acquired transient factor X (Stuart factor) deficiency in a patient with mycoplasma pneumonial infection. Scand J Haematol 23(4):257-264 
2. Uprichard J, Perry DJ (2002) Factor X deficiency. Blood Rev 16(2):97-110

3. Bohler A, Lammle B (1999) Decreased quick percentage, acquired factor $\mathrm{X}$ deficiency, haemarthrosis and ecchymosis; amyloidosis. Ther Umsch 56(9):523-525

4. Kouides PA, Kulzer L (2001) Prophylactic treatment of severe factor $\mathrm{X}$ deficiency with prothrombin complex concentrate. Haemophilia 7(2):220-223

5. Bajaj SP, Joist NH (1999) New insights into how blood clots: implications for the use of APTT and PT as coagulation screening tests and in monitoring of anticoagulant therapy. Semin Thromb Hemost 25(4):407-418

6. Hertzberg M (1994) Biochemistry of factor X. Blood Rev $8(1): 56-62$

7. Saligsohn U, White GC (2001) Inherited deficiencies of coagulation factors II, V, VII, XI and XIII and the combined deficiencies of Factors V and VIII and of the Vitamin $\mathrm{K}$ dependent factors. In: Beutler E, Lichtman MA, Coller BS, Kipps TJ, Seligsohn U (eds) Williams Hematology, 6th edn, International edition. McGraw-Hill Medical Publishing Division, New York, pp 1617-1638

8. Perry DJ (2005) Factor $X$ and Factor $X$ deficiency. In: Christine AL, Erik EB, Hoots WK (eds) Text book of Hemophilia, 1st edn. Blackwell, Oxford, pp 315-320

9. Kumar A, Mishra KL, Kumar A, Mishra D (2005) Hereditary coagulation factor $\mathrm{X}$ deficiency. Indian Pediatr 42(12):1240-1242

10. Bolton-Maggs PH, Perry DJ, Chalmers EA, Parapia LA, Wilde JT, Williams MD et al (2004) The rare coagulation disorders-review with guidelines for management from the
United Kingdom Haemophilia Centre Doctors' Organisation. Haemophilia 10(5):593-628

11. Perry DJ (1997) Factor X and its deficiency states. Haemophilia 3:159-172

12. Peyvandi F, Mannucci PM, Lak M, Abdoullahi M, Zeinali S, Sharifian R, Perry D (1998) Congenital factor X deficiency: spectrum of bleeding symptoms in 32 Iranian patients. Br J Haematol 102(2):626-628

13. Kohler M (1999) Thrombogenicity of prothrombin complex concentrates. Thromb Res 95(4 Suppl 1):S13-S17

14. Kessler C (2007) Hemorrhagic disorders: coagulation factor deficiencies, chap 180. In: Goldman L, Ausiello D (eds) Cecil Medicine, 23rd edn. Philadelphia, Saunders Elsevier

15. Takabe K, Holman PR, Herbst KD, Glass CA, Bouvet M (2004) Successful perioperative management of factor X deficiency associated with primary amyloidosis. J Gastrointest Surg 8:358-362

16. Nomura K, Liu N, Nagai K, Hasegawa T et al (2007) Roles of coagulation pathway and factor $\mathrm{Xa}$ in rat mesangioproliferative glomerulonephritis. Lab Invest 87(2):150-160

17. Tanaka M, Arai H, Liu N, Nogaki F et al (2005) Role of coagulation factor $\mathrm{Xa}$ and protease-activated receptor 2 in human mesangial cell proliferation. Kidney Int 67(6): 2123-2133

18. Zipfel P, Smith R, Heinen S (2006) The role of complement in membranoproliferative glomerulonephritis. Complement and kidney. Progress in inflammation research, Springer, Berlin, pp 199-221 